\title{
BMJ Open Associations of functional disability and behavioural risk factors with social participation of older adults: a cross- sectional analysis from the Canadian Longitudinal Study on Aging
}

\author{
Parminder Raina, ${ }^{1}$ Muhammad Usman Ali, ${ }^{1}$ Divya Joshi $\quad$ (D),${ }^{1}$ Anne Gilsing, ${ }^{1}$ \\ Alexandra Mayhew, ${ }^{1}$ Mary Thompson, ${ }^{2}$ Lauren E Griffith (D) ${ }^{1}$
}

To cite: Raina P, Ali MU, Joshi D, et al. Associations of functional disability and behavioural risk factors with social participation of older adults: a cross-sectional analysis from the Canadian Longitudinal Study on Aging. BMJ Open 2022;12:e052173. doi:10.1136/ bmjopen-2021-052173

- Prepublication history and additional supplemental materia for this paper are available online. To view these files, please visit the journal online (http://dx.doi.org/10.1136/ bmjopen-2021-052173)

Received 07 April 2021 Accepted 05 January 2022

D Check for updates

(C) Author(s) (or their employer(s)) 2022. Re-use permitted under CC BY-NC. No commercial re-use. See rights and permissions. Published by BMJ.

${ }^{1}$ Department of Health Research Methods, Evidence, and Impact, McMaster University, Hamilton, Ontario, Canada

${ }^{2}$ Department of Statistics and Actuarial Science, University of Waterloo, Waterloo, Ontario, Canada

Correspondence to Dr Parminder Raina; praina@mcmaster.ca

\section{ABSTRACT}

Objectives To examine: (1) the associations of functional disability and behavioural risk factors with social participation; and (2) whether the association between functional disability and social participation is modified by co-occurrence of behavioural risk factors.

Design A cross-sectional analysis of data from the Canadian Longitudinal Study on Aging.

Setting A national stratified sample of 51388 individuals living in the 10 Canadian provinces at the time of baseline data collection (2011-2015).

Participants Participants included men and women aged 45-85 years and residing in the communities in the 10 Canadian provinces.

Outcome measures Social participation was assessed using frequency of participant involvement in eight different social activities in the past 12 months. Responses for each category were converted into number of days per month. Total social participation score (range: 0-180) was based on summing frequencies over all eight activities representing number of social activities per month.

Results Functional disability was associated with participating in fewer social activities (difference in mean total social participation score, $b=-1.1,95 \%$ $\mathrm{Cl}-1.5$ to -0.7$)$. In comparison to no behavioural risk factors, presence of any one $(b=-2.7,95 \% \mathrm{Cl}-3.1$ to -2.3$)$, any two $(b=-4.6,95 \% \mathrm{Cl}-5.0$ to -4.2$)$, any three $(b=-6.3,95 \% \mathrm{Cl}-6.8$ to -5.9$)$ and all four $(b=-7.8,95 \% \mathrm{Cl}-9.0$ to -6.6$)$ behavioural risk factors was associated with lower social participation. The association between functional disability and social participation was modified by the presence of behavioural risk factors with the lowest social participation observed for adults with disability and all four behavioural risk factors $(b=-4.3,95 \% \mathrm{Cl}-7.5$ to $-1.2)$.

Conclusions Individuals with functional disabilities and behavioural risk factors are more likely to experience restrictions in social participation. Public health interventions that encourage healthy lifestyle behaviours may help mitigate the impact of functional disabilities on social participation in the ageing population.

\section{Strengths and limitations of this study}

- This study addresses the gap for empirical research by examining the associations of functional disability and co-occurrence of behavioural risk factors with social participation in older adults.

- This study included a large, population-based sample to examine the associations of functional disability and behavioural risk factors with social participation of older adults.

- The analyses were based on the baseline crosssectional data; therefore, the associations between functional disability, behavioural risk factors and social participation may be subject to reverse causality.

- The study sample did not include individuals residing in long-term care institutions, which may have underestimated the association between functional disability and social participation and limit the generalisability of our findings to community-dwelling populations.

\section{INTRODUCTION}

Social participation is viewed as an important factor impacting the health and well-being of older individuals. ${ }^{1-4}$ Epidemiological evidence suggests that participation in meaningful social activities is associated with lower risk of physical and mental health problems, loneliness, frailty, disability, and mortality, and better health-related behaviours, quality of life, life satisfaction and self-rated health. ${ }^{5-7}$ The WHO has recognised the direct impact of social participation on health and well-being and has thus integrated it into research and policy frameworks of ageing. ${ }^{8}$ For instance, the Decade of Health Ageing 2021-2030, an initiative led by the WHO to foster healthy ageing, recognises the need to create a wide 
range of affordable and accessible opportunities for social participation as part of their action strategy to enable older adults to live independently and age in place of choice by building age-friendly cities and communities. ${ }^{8}$

Despite the strong positive association of social participation with health and well-being, opportunities for social participation tend to decline with age, particularly among those with diminished physical capacity. ${ }^{9}$ According to the Canadian Study on Health and Aging, 15.4\% of Canadians aged 65 years and older reported having at least one disability in basic activity of daily living (ADL) and 33.4\% reported having at least one disability in instrumental activities of daily living (IADL).$^{10}$ Many older individuals also live with multiple chronic mental and physical health conditions, which has a significant impact on their ability to perform ADL, and as a result experience reduced opportunities to participate in formal and informal social activities. ${ }^{11}$ Additionally, external factors such as cost and availability of social activities, accessibility and the physical built environment may also act as barriers for social participation among adults with functional disabilities. ${ }^{112}$ Findings from meta-analyses and systematic reviews also indicate that functional disabilities may be associated with behavioural risk factors including physical inactivity and smoking. ${ }^{12}$ The evidence for the association of physical inactivity, sedentary behaviour, obesity, nutritional behaviour and smoking with functional disability is compelling; however, the association between alcohol consumption and functional disability in older adults is less clear. ${ }^{12-16}$ Some studies found alcohol consumption to be associated with greater risk of functional disability, whereas other studies reported light to moderate alcohol consumption to be associated with maintenance of mobility compared with non-drinkers, ${ }^{13} 1718$ but only in older adults in good health. In addition to functional disabilities, research indicates that health behaviours may also be associated with social participation among older adults. Some studies have shown higher levels of social engagement to be positively associated with participation in moderate to vigorous level of physical activity and a daily intake of at least five servings of fruits and vegetables, ${ }^{19} 20$ and negatively associated with smoking, ${ }^{20} 21$ while other studies reported no associations or inconsistent findings. ${ }^{22-24}$

To develop and implement strategies for increasing social participation as individuals age, it is critical to understand the factors that contribute to lower social participation. To date, there is little empirical research about whether functional disability impacts social participation in an ageing population. Further, studies have examined the independent effects of behavioural risk factors on functional disabilities and social participation, but to our knowledge no study has examined whether co-occurrence of behavioural risk factors influences the association between functional disability and social participation in the adult population. Therefore, the purpose of this study was to investigate the associations between functional disability, behavioural risk factors including smoking, physical inactivity, low nutritional intake, and high-risk alcohol consumption, and social participation, and to examine whether the association between functional disability and social participation is modified by co-occurrence of behavioural risk factors.

\section{METHODS}

\section{Data source and participants}

The Canadian Longitudinal Study on Aging (CLSA) is a population-based study, which recruited a generalisable, stratified random sample of 51338 community-dwelling individuals aged 45-85 years at baseline (2011-2015). The CLSA cohort consists of the Tracking cohort of 21241 participants who were randomly recruited from the 10 Canadian provinces, and the Comprehensive cohort of 30097 participants who were randomly recruited from one of 11 data collection sites in seven provinces. ${ }^{25}$ Residents of the three Canadian territories, individuals living on First Nation reserves or in long-term care institutions, full-time members of the armed forces, those unable to respond in either English or French and those with significant cognitive impairment were excluded from the study. Details on the study design have been described elsewhere. ${ }^{25}$ All 51338 participants were included in the analyses, which was conducted from May to August 2020.

\section{Social participation}

Informal social participation generally refers to interactions with personal and close relationships such as with family members, friends, neighbours and coworkers, whereas formal social participation refers to interactions with established organisations such as with religious, sports, education or other community organisations. ${ }^{26}$ Social participation was estimated using frequency of participant involvement in eight different social activities in the past 12 months. ${ }^{26}$ The social activities included: (1) family or friendship activities outside the household; (2) church or religious activities; (3) sports/physical activities with other people; (4) educational or cultural activities involving other people; (5) service club or fraternal organisation activities; (6) neighbourhood, community or professional association activities; (7) volunteer or charity work; and (8) other recreational activities involving other people (hobbies, gardening, cards). Responses for each category were converted into number of days per month as follows: 'almost every day': 20, 'at least once a week': 6 , 'at least once a month': 2 , 'at least once a year': 1 and 'never': 0. Total social participation score is based on summing frequencies over all eight activities representing number of social activities per month, and may range from 0 to 180 . The social participation scale based on total score has good internal consistency with Cronbach's $\alpha$ of 0.85 and a difference of 0.5 activities per person is considered relevant. ${ }^{27}$ 


\section{Functional disability}

Functional disability was assessed using a 14-item questionnaire adapted from the Older Americans Resources and Services Multidimensional Assessment Questionnaire. ${ }^{28}$ The questionnaire included seven items pertaining to ADL and seven items pertaining to IADL (online supplemental table 1). Participants who reported requiring assistance with at least one ADL or IADL were considered as having a functional disability.

\section{Behavioural risk factors}

Cigarette smoking was categorised as non-smoker (including never smoker and former occasional smoker who smoked 1 or more cigarettes in their lifetime) and smoker (including current occasional smoker who smoked 100 or less cigarettes in their lifetime, current daily smoker, and former daily smoker) ${ }^{29}$

Nutritional risk was assessed using the 'Seniors in the Community: Risk Evaluation for Eating and Nutrition (SCREEN-II) ' tool ${ }^{30}$ SCREEN-II is reliable and valid for assessing nutritional risk in community-dwelling older adults. This tool assesses weight loss or gain, frequency of skipping meals, appetite, difficulties in eating, intake of fluids and fruits and vegetables, frequency of eating meals alone, meal preparation, and satisfaction with quality of food prepared by others. Participants who had a total score of less than 32 were identified as having high nutritional risk, and this cut-off is validated and was recommended through personal communication with the developer of SCREEN-II.

Physical activity was measured using the Physical Activity Scale for the Elderly (PASE), which assesses the frequency, intensity, and duration of participantion in leisure, household work, and volunteer activities within the past week. ${ }^{31}$ Individuals who participated in at least $75 \mathrm{~min}$ per week of vigorous-intensity physical activity or $150 \mathrm{~min}$ per week of combined moderate-intensity and vigorous-intensity physical activities were considered to have adequate physical activity, otherwise they were considered to have low physical activity. ${ }^{32} 33$

Alcohol consumption was assessed using Canadian Centre on Substance Use and Addiction guidelines on 'Knowing Your Limits with Alcohol'. ${ }^{34}$ Participants were either categorised as low-risk drinkers (never drinker, light drinkers defined as consuming 1-15 drinks a week for men and 1-10 drinks per week for women) or highrisk drinkers (moderate/heavy drinkers defined as consuming more than 15 drinks per week for men and more than 10 drinks per week for women).

\section{Other covariates and confounders}

Age (45-54, 55-64, 65-74 and 75+ years); sex; body mass index (BMI; <25, 25-30 and $>30 \mathrm{~kg} / \mathrm{m}^{2}$ ); number of chronic conditions from 13 disease categories including musculoskeletal, respiratory, cardiac, vascular, endocrine, neurological, gastrointestinal, genitourinary, ophthalmological, psychiatric, kidney disease, back problems and cancer (0, 1, 2, 3 and more conditions); remoteness (urban or rural setting); marital status (single or never lived with a partner, married/living with a partner in common-law relationship, widowed or divorced/separated); retirement status (retired, retired and returned to work or not retired); social inequality (assessed using the MacArthur Scale of Subjective Social Status with scores of 1-4 categorized as 'bad', 5-6 as 'regular', 7-8 as 'good' and $9-10$ as 'very good') ${ }^{35} 36$; total annual household income $(<\$ 20000, \$ 20 \quad 000-<\$ 50 \quad 000, \$ 50 \quad 000-<\$ 100$ $000, \$ 100000-<\$ 150000$ or $>=\$ 150000)$; and education level (less than secondary school, secondary school, some postsecondary diploma/certification or postsecondary degree) were included as covariates.

\section{Data analysis}

Analyses were conducted using STATA (V.16.0, StataCorp, College Station, Texas, USA). The CLSA sampling weights (inflation weights for descriptive analysis and analytical weights for any statistical modelling or testing) were incorporated into all the analyses as appropriate. The chained equations algorithm with a fully conditional specification technique for multiple imputation $(n=20)$ was used for missing data $(\mathrm{n}=5654 ; 11 \%)$ using all variables described above (online supplemental table 2).$^{37}$ Categorical variables were summarised using frequency and percentages. Continuous data were summarised using mean and SD.

To examine the associations between social participation, functional disability and behavioural risk factors, a series of multivariable linear regression models were conducted using the analytical weights with social participation as a continuous outcome, and disability and four behavioural risk factors as the primary exposure variables. To further examine the extent to which the association between social participation and disability is modified by the behavioural risk sets, two-way interaction between disability and number of risk factors present (ranging from 0 to 4 ) were included in the regression models. All multivariable analyses were adjusted for covariates identified a priori in the literature for their association with functional disability and are listed above. All models were first adjusted for preselected core variables including urban/rural status, marital status, retirement status, BMI, social inequality, income level, education level, and age and sex (for models that were not stratified by age and sex), and then further adjusted for behavioural risk factors, and number of chronic conditions. The model stability and the goodness-of-fit model were evaluated graphically (residuals plots) and using statistics (likelihood ratio test, deviance, Akaike's Information Criteria (AIC) and Bayesian Information Criteria (BIC) criteria).

\section{Patient and public involvement}

Patients or the public were not involved in the design, or conduct, or reporting, or dissemination plans of our research. 


\section{RESULTS}

\section{Participant characteristics}

Of the participants who were classified as having functional disability, majority of them (8.2\%) had mild impairment (1-3 ADL or IADL problems), about $1.0 \%$ had moderate impairment (4-5 ADL/IADL problems) and $0.3 \%$ had severe impairment (6 or more ADL/IADL problems). Characteristics of the study population by social participation and social participation by functional disability status are presented in table 1. Overall, older adults in the CLSA cohort $(\mathrm{n}=51338)$ participated in a mean number of 19.4 social participation in activities per month. This mean was lower for the participants with functional disability than those without disability (17.2 vs 19.6, respectively). For participants with functional disability, the mean number of social participation in activities per month was lower among the 45-54 age group (15.5), men (15.5) and individuals with all four behavioural (high nutritional risk, low physical activity, smokers and current alcohol use) risk factors (11.0).

\section{Associations between social participation, functional disability and behavioural risk factors}

Regression estimates representing difference in mean total social participation score, and 95\% CIs for the associations of functional disability and behavioural risk factors with social participation are presented in table 2. Functional disability was associated with participating in fewer social activities ( $\mathrm{b}=-1.1,95 \%$ CI -1.5 to -0.7$)$. All four risk factors were also associated with fewer social participation activities with an adjusted regression coefficient of -1.4 (95\% CI -1.6 to -1.2 ) for smoking, -3.8 (95\% CI -4.1 to -3.6$)$ for low physical activity, -1.8 (95\% CI -2.2 to -1.4$)$ for high nutritional risk and $-0.7(95 \%$ CI -1.0 to -0.3 ) for high-risk drinking. A similar trend was observed for the association between the number of risk factors and social participation. The regression estimates showed a consistent gradient with the number of risk factors present when compared with those with no risk factors: -2.7 (95\% CI -3.1 to -2.3 ) when any one risk factor was present, -4.6 (95\% CI -5.0 to -4.2$)$ when any two factors were present, -6.3 (95\% CI -6.8 to -5.9$)$ when any three risk factors were present and -7.8 (95\% CI -9.0 to -6.6 ) when all four risk factors were present.

The stratified analyses based on four behavioural risk factors showed that functional disability with each behavioural risk factor present was associated with participating in fewer social activities than functional disability without risk factor present (table 2). The association between functional disability and social participation was statistically significantly modified by the presence of behavioural risk factors. We found an interaction between disability and the number of risk factors present with the lowest social participation observed for older adults with disability and all four risk factors present (table 2, figure 1). Figure 1 shows the marginal effects (linear predictive margins with 95 CIs) for social participation at each combination of number of risk factors present and functional disability status. The regression estimates showed a statistically significant decrease from $2.0(95 \%$ CI -0.4 to 3.9) for disability and no risk factors present as main effects to -2.9 (95\% CI -5.1 to -0.8 ) for interaction between disability and any one risk factor present, -3.7 (95\% CI -5.8 to -1.5$)$ for interaction between disability and any two risk factors present, -3.9 (95\% CI -6.2 to $-1.7)$ for interaction between disability and any three risk factors present and -4.3 (95\% CI -7.5 to -1.2$)$ for interaction between disability and all four risk factors present.

We conducted sensitivity analyses exploring the association between severity of functional disability and social participation (online online supplemental table 3 , figure 1$)$. The results showed a gradient association, with individuals with mild impairment (1-3 ADL/IADL problems; $\mathrm{b}=-0.82,95$ CI -1.25 to -0.39$)$, moderate impairment (4-5 ADL/IADL problems; $\mathrm{b}=-3.68,95 \% \mathrm{CI}$ -4.87 to -2.49 ) and severe impairment (6 or more ADL/ IADL; $b=-5.47,95 \%$ CI -7.44 to -3.49 ) participating in fewer social activities compared with those with no functional disability after adjusting for covariates. Further, we explored the associations between functional disability, behavioural risk factors and social participation stratified by age and sex (online online supplemental table 4 and 5). After adjusting for all covariates, functional disability was associated with lower social participation in all subgroups, but the association was stronger in older compared with younger individuals. The results for the association between behavioural risk factors and social participation were largely consistent with those reported for the overall sample. We also explored the associations of functional disability and behavioural risk factors on subtypes of social participation activities. Overall, there was no meaningful difference in the associations by social participation subtypes (online online supplemental table 6 and 7$)$.

\section{DISCUSSION}

This is the first study to examine the associations between functional disability, behavioural risk factors and social participation among middle to older aged adults using a nationally generalisable sample. Our study found that functional disability and behavioural risk factors including smoking, low physical activity, high nutritional risk and high-risk alcohol consumption were associated with lower social participation. Of the four risk factors, low physical activity had the greatest influence on social participation. Moreover, we found that the greater the number of behavioural risk factors that were present, the lower the social participation, suggesting a gradient relationship. The results of our study also demonstrated that the association between functional disability and social participation was modified by the number of behavioural risk factors present. Individuals with functional disability who had all four risk factors experienced the lowest social participation. 
Table 1 Characteristics of the study population by social participation and social participation by functional disability status

\begin{tabular}{|c|c|c|c|}
\hline \multirow[b]{2}{*}{ Variables } & \multirow{2}{*}{$\begin{array}{l}\text { Overall social } \\
\text { participation, mean (SD) } \\
(n=51291)\end{array}$} & \multicolumn{2}{|c|}{ Social participation by functional disability status, mean (SD) } \\
\hline & & Functional disability $(n=5207$ ) & No functional disability $(n=45705)$ \\
\hline Overall & $19.4(12.4)$ & $17.2(13.1)$ & $19.6(12.4)$ \\
\hline \multicolumn{4}{|l|}{ Age group } \\
\hline $45-54$ & $18.7(11.8)$ & $15.5(12.3)$ & $18.9(11.8)$ \\
\hline $55-64$ & $19.0(12.4)$ & $17.2(14.0)$ & $19.1(12.2)$ \\
\hline $65-74$ & $20.9(13.2)$ & $18.1(13.7)$ & $21.3(13.1)$ \\
\hline $75-85$ & $20.0(12.9)$ & $17.8(12.3)$ & $20.8(13.0)$ \\
\hline \multicolumn{4}{|l|}{ Sex } \\
\hline Male & $18.7(12.3)$ & $15.5(13.2)$ & $18.9(12.3)$ \\
\hline Female & $20.0(12.5)$ & $17.9(13.0)$ & $20.4(12.4)$ \\
\hline \multicolumn{4}{|l|}{ Smoking } \\
\hline Yes & $18.1(12.3)$ & $15.7(12.4)$ & $18.4(12.3)$ \\
\hline No & $20.6(12.4)$ & $18.9(13.6)$ & $20.8(12.3)$ \\
\hline \multicolumn{4}{|l|}{ Low physical activity } \\
\hline Yes & $18.1(11.9)$ & $16.7(12.8)$ & $18.4(11.8)$ \\
\hline No & $22.5(12.9)$ & $23.3(14.6)$ & $22.5(12.8)$ \\
\hline \multicolumn{4}{|l|}{ High nutritional risk } \\
\hline Yes & $16.2(12.0)$ & $14.2(12.6)$ & $16.8(11.9)$ \\
\hline No & $20.0(12.4)$ & $19.1(13.1)$ & $20.1(12.3)$ \\
\hline \multicolumn{4}{|l|}{ Alcohol consumption } \\
\hline High-risk drinking & $19.1(12.2)$ & $16.7(12.0)$ & $19.2(12.2)$ \\
\hline Low-risk drinking & $19.4(12.3)$ & $17.3(13.2)$ & $19.7(12.4)$ \\
\hline \multicolumn{4}{|c|}{ Behavioural risk factors present (n) } \\
\hline 0 & $23.5(13.3)$ & $26.1(16.8)$ & $23.4(13.1)$ \\
\hline 1 & $20.3(12.0)$ & $19.6(12.6)$ & $20.3(11.9)$ \\
\hline 2 & $18.1(12.0)$ & 16.7 (11.9) & $18.2(12.0)$ \\
\hline 3 & $15.8(11.7)$ & $14.3(13.4)$ & $16.1(11.3)$ \\
\hline 4 & $14.2(12.2)$ & $11.0(8.0)$ & $15.0(12.9)$ \\
\hline \multicolumn{4}{|l|}{ Built environment } \\
\hline Rural & $18.8(12.3)$ & $16.5(12.8)$ & $19.1(12.2)$ \\
\hline Urban & $19.5(12.5)$ & $17.4(13.1)$ & $19.8(12.4)$ \\
\hline \multicolumn{4}{|l|}{ Marital status } \\
\hline Married/common-law & $19.8(12.4)$ & $17.7(13.2)$ & $20.0(12.3)$ \\
\hline Single & $16.6(11.7)$ & $15.0(13.4)$ & $16.8(11.5)$ \\
\hline Widowed & $20.2(13.1)$ & $18.5(12.3)$ & $20.8(13.3)$ \\
\hline Divorced/separated & $18.0(12.6)$ & $15.2(12.8)$ & $18.4(12.5)$ \\
\hline \multicolumn{4}{|l|}{ Retirement status } \\
\hline Retired & $20.1(13.0)$ & $17.1(13.5)$ & 20.7 (12.9) \\
\hline Retired/return to work & $21.8(13.2)$ & $19.3(12.7)$ & $22.0(13.3)$ \\
\hline Not retired & $18.4(11.7)$ & $16.6(12.2)$ & $18.5(11.7)$ \\
\hline \multicolumn{4}{|l|}{ Body mass index $\left(\mathrm{kg} / \mathrm{m}^{2}\right)$} \\
\hline$<25$ & $19.8(12.4)$ & $18.0(14.1)$ & $20.0(12.3)$ \\
\hline $25-30$ & $19.7(12.5)$ & $18.2(13.5)$ & $19.8(12.4)$ \\
\hline$>30$ & $18.3(12.3)$ & $15.9(11.9)$ & $18.7(12.4)$ \\
\hline
\end{tabular}


Table 1 Continued

\begin{tabular}{|c|c|c|c|}
\hline \multirow[b]{2}{*}{ Variables } & \multirow{2}{*}{$\begin{array}{l}\text { Overall social } \\
\text { participation, mean (SD) } \\
(\mathrm{n}=51291)\end{array}$} & \multicolumn{2}{|c|}{ Social participation by functional disability status, mean (SD) } \\
\hline & & Functional disability $(n=5207)$ & No functional disability $(n=45705)$ \\
\hline \multicolumn{4}{|l|}{ Social inequality } \\
\hline $\operatorname{Bad}(1-4)$ & $15.0(11.0)$ & $13.6(11.4)$ & $15.3(10.9)$ \\
\hline Regular (5-6) & $18.7(11.5)$ & $17.6(12.1)$ & $18.8(11.5)$ \\
\hline Good (7-8) & $21.9(12.5)$ & $21.9(14.3)$ & $21.9(12.4)$ \\
\hline Very good (9-10) & $24.6(15.5)$ & $25.1(17.3)$ & $24.6(15.4)$ \\
\hline \multicolumn{4}{|l|}{ Annual household income } \\
\hline$<\$ 20000$ & $15.3(12.8)$ & $13.2(12.7)$ & $16.1(12.8)$ \\
\hline$\geq \$ 20000$ to $<\$ 50000$ & $18.2(12.6)$ & $17.4(13.5)$ & $18.3(12.5)$ \\
\hline$\geq \$ 50000$ to $<\$ 100000$ & $19.5(12.2)$ & $18.1(11.8)$ & $19.6(12.2)$ \\
\hline$\geq \$ 100000$ to $<\$ 150000$ & $20.0(12.2)$ & $18.6(14.2)$ & $20.1(12.1)$ \\
\hline$\geq \$ 150000$ & $21.2(12.1)$ & $19.2(12.0)$ & $21.3(12.1)$ \\
\hline \multicolumn{4}{|l|}{ Education level } \\
\hline Less than secondary & $16.1(12.2)$ & $13.3(11.8)$ & $16.8(12.2)$ \\
\hline Secondary only & $17.0(12.1)$ & $15.6(11.7)$ & $17.2(12.2)$ \\
\hline Some postsecondary & $19.1(12.8)$ & $17.3(14.7)$ & $19.3(12.5)$ \\
\hline Postsecondary degree & $20.2(12.4)$ & $18.5(13.2)$ & $20.3(12.3)$ \\
\hline \multicolumn{4}{|l|}{ Chronic conditions (n) } \\
\hline 0 & $20.0(12.4)$ & $21.6(14.9)$ & $20.0(12.3)$ \\
\hline 1 & $19.9(12.3)$ & $20.3(14.7)$ & $19.9(12.2)$ \\
\hline 2 & $19.4(12.0)$ & $18.6(12.0)$ & $19.4(12.0)$ \\
\hline 3 or more & $18.9(12.7)$ & $16.7(13.0)$ & $19.4(12.6)$ \\
\hline
\end{tabular}

Our finding that functional disability is associated with lower social participation is consistent with literature. $^{38}{ }^{39}$ Many reasons including health concerns may explain lower social participation among people with functional disabilities. Research shows older individuals with functional disabilities are more likely to have multiple chronic conditions and spend more time in managing their conditions, which may affect their ability to participate in social activities. ${ }^{11}$ Data from the CLSA Comprehensive cohort showed that $50.4 \%$ of people with functional disability compared with $10.9 \%$ of people without functional disability reported health limitations as a factor in preventing participation in social activities. Further, the ability to participate in formal and informal social activities depends on the offer of activities, and on being able to afford and access the activities. ${ }^{40}$ Research shows that people with disabilities are more likely to have limited financial resources, perhaps due to barriers in employment, thus lowering their opportunities to participate in social activities. ${ }^{40}$ Further, lower social participation among people with functional disabilities may be related to environmental barriers, including structural barriers and inaccessible environments, discriminating attitudes, availability of information and knowledge, and organisational policies and practices. ${ }^{38}$ Research also indicates that the association between functional disability and social participation may be bidirectional and more complex where losses in functional capabilities may result in reduced social participation, which in turn may accelerate functional decline. ${ }^{41}{ }^{42}$ Given that lower social participation is associated with poor health and well-being, these findings emphasise the need to identify factors that can help guide interventions.

Our results show that behavioural risk factors including smoking, low physical activity, high nutritional risk and high-risk drinking were individually and cumulatively associated with lower social participation and modified the association between social participation and functional disabilities. The association between behavioural risk factors and reduced social participation is consistent with the literature. ${ }^{19-21}$ Research suggests that older adults who have an unhealthy dietary pattern and are physically inactive are more likely to experience health concerns, have mobility restrictions, have financial constraints, lack social support or be socially isolated, which may result in reduced opportunities to participate in social activities. ${ }^{204344}$ Studies have also shown that participating in physical activities provides people with more opportunities for social interaction and participation. ${ }^{19}$ Thus, people who are physically inactive may miss out on these opportunities for social participation. Further, behaviours such as smoking and high-risk drinking may be viewed as 
Table 2 Association of functional disability and behavioural risk factors with social participation

$b^{*}(95 \% \mathrm{Cl})$

$n=51338$

\begin{tabular}{|c|c|}
\hline \multicolumn{2}{|l|}{ Overall } \\
\hline \multicolumn{2}{|l|}{ Functional disability (Yes vs No) } \\
\hline Unadjusted & $-2.1(-2.5$ to -1.7$)$ \\
\hline Adjusted for core variables $\dagger$ & $-1.7(-2.1$ to -1.3$)$ \\
\hline $\begin{array}{l}\text { Adjusted for core variables and number of } \\
\text { chronic conditions }\end{array}$ & $-1.5(-1.9$ to -1.1$)$ \\
\hline $\begin{array}{l}\text { Adjusted for core variables and behavioural } \\
\text { risk factors }\end{array}$ & $-1.2(-1.6$ to -0.8$)$ \\
\hline $\begin{array}{l}\text { Adjusted for core variables, number of } \\
\text { chronic conditions and behavioural risk } \\
\text { factors (fully adjusted model) } \ddagger\end{array}$ & $-1.1(-1.5$ to -0.7$)$ \\
\hline
\end{tabular}

Behavioural risk factorsł

\begin{tabular}{ll}
\hline Smoking versus no smoking & $-1.4(-1.6$ to -1.2$)$ \\
\hline Low versus recommended physical activity & $-3.8(-4.1$ to -3.6$)$ \\
\hline High versus no nutritional risk & $-1.8(-2.2$ to -1.4$)$ \\
\hline High versus low-risk drinking & $-0.7(-1.0$ to -0.3$)$ \\
\hline Behavioural risk factors present $(\mathrm{n})$ & \\
\hline Any 1 versus none & $-2.7(-3.1$ to -2.3$)$ \\
Any 2 versus none & $-4.6(-5.0$ to -4.2$)$ \\
\hline Any 3 versus none & $-6.3(-6.8$ to -5.9$)$ \\
\hline All 4 versus none & $-7.8(-9.0$ to -6.6$)$
\end{tabular}

Stratified analysis§

By smoking statusł

Smoker $\quad-1.3(-1.8$ to -0.8$)$

Non-smoker $\quad-0.8(-1.4$ to -0.2$)$

By physical activity levelł

\begin{tabular}{ll} 
Low physical activity & $-1.2(-1.7$ to -0.8$)$ \\
Recommended physical activity & $-0.1(-1.3$ to -0.6$)$ \\
By nutritional risk $\neq$ & \\
No nutritional risk & $-1.5(-2.4$ to -0.7$)$ \\
\hline
\end{tabular}

By alcohol consumption $\ddagger$

\begin{tabular}{ll}
\hline Low-risk drinking & $-1.1(-2.4$ to 0.3$)$ \\
\hline High-risk drinking & $-1.1(-1.5$ to -0.7$)$ \\
\hline $\begin{array}{l}\text { Interaction analysis } \neq \\
\begin{array}{l}\text { Functional disability with one behavioural risk } \\
\text { factor }\end{array}\end{array}$ & $-2.9(-5.1$ to -0.8$)$ \\
$\begin{array}{l}\text { Functional disability with two behavioural risk } \\
\text { factors }\end{array}$ & $-3.7(-5.8$ to -1.5$)$ \\
$\begin{array}{l}\text { Functional disability with three behavioural } \\
\text { risk factors }\end{array}$ & $-3.9(-6.2$ to -1.7$)$ \\
$\begin{array}{l}\text { Functional disability with four behavioural risk } \\
\text { factors }\end{array}$ & $-4.3(-7.5$ to -1.2$)$ \\
\hline
\end{tabular}

${ }^{*}$ Regression coefficients are the difference in mean social participation score. †Adjusted for core variables: age, sex, urban/rural setting, marital status, retirement status, body mass index (BMI), social inequality, income and education level.

¥Fully adjusted model: adjusted for core variables, behavioural risk factors and number of chronic conditions.

$\S S t r a t i f i e d$ analysis presents the effects of functional disability on social participation in the different strata of each behavioural risk factor in the fully adjusted model.

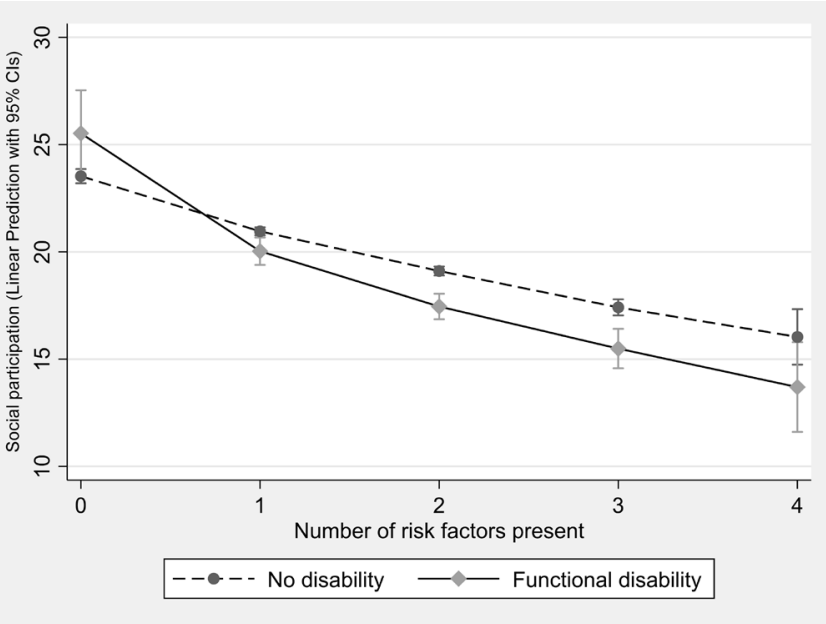

Figure 1 Association of social participation and number of behavioural risk factors by functional disability status.

socially unacceptable or undesirable, which may explain the lower social participation among adults engaging in these behaviours. ${ }^{21}$ Although these results demonstrate that accumulation of behavioural risk factors and presence of functional disability have a synergistic effect on the decline in social participation, longitudinal studies are needed to examine whether intervening on behavioural risk factors in people with functional disability would help prevent or lessen the impact of functional disabilities on social participation.

\section{Strengths and limitations}

Our analyses were based on the baseline cross-sectional data (at the time of these analyses, CLSA had only baseline data available). The associations between functional disability, behavioural risk factors and social participation may be bi-directional, and thus causal inference cannot be made. Further, behavioural risk factors were dichotomised in the analysis based on clinically relevant and validated cut-points; however, dichotomisation may have resulted in loss of information about individual differences within the groups and increase the chance of misclassifying some participants. Of the participants who had functional disability, majority of them reported mild impairment. Thus, we were unable to explore interactions between severity of functional disability and number of health behaviours stratified by age and sex. The study sample did not include individuals residing in long-term care institutions, which may have underestimated the association between functional disability and social participation and limit the generalisability of our findings to the general community-dwelling middle-aged and older adult populations. Nevertheless, this study included a large, population-based sample, used validated tools to assess study variables, and adjusted for a number of potential confounders to examine the association of functional disability and behavioural risk factors with social participation of older adults. 


\section{CONCLUSIONS}

The results of this study provide evidence that individuals with functional disabilities and behavioural risk factors are more likely to experience restrictions in social participation. The results also indicate that the greater the co-occurrence of behavioural risk factors, the lower the social participation. Further, the association between functional disability and social participation varies by the number of behavioural risk factors present. Individuals with functional disability and all four risk factors are prone to experiencing the lowest social participation. Given that social participation is a key component of healthy ageing, longitudinal studies are needed to identify whether public health intervention strategies targeting modifiable behavioural risk factors may help prevent or lower the impact of functional disabilities on social participation in the ageing population.

\section{Twitter Lauren E Griffith @LaurenGriff1}

Contributors PR, MUA, AM, AG and LEG were involved in the conceptualisation and design of the study. PR, MUA, MT and LEG conducted the data analyses. PR and DJ drafted the manuscript. All authors contributed to the interpretation of the data, provided critical revisions of the manuscript and approved the final version to be published. PR will serve as a guarantor for the contents of this article.

Funding Funding for the Canadian Longitudinal Study on Aging (CLSA) is provided by the Government of Canada through the Canadian Institutes of Health Research (CIHR) under grant reference LSA 94473, the Canada Foundation for Innovation and provincial governments (Newfoundland, Nova Scotia, Quebec, Ontario, Manitoba, Alberta and British Columbia). This research has been conducted using the CLSA Baseline Tracking Dataset version 3.2 and Baseline Comprehensive Dataset version 3.2 under application number 161016. The CLSA is led by Dr Parminder Raina, Dr Christina Wolfson and Dr Susan Kirkland. This work was supported by the CIHR Catalyst Grant under grant reference ACD-151285. Parminder Raina holds the Raymond and Margaret Labarge Chair in Optimal Aging and Knowledge Application for Optimal Aging, is the Director of the McMaster Institute for Research on Aging and the Labarge Centre for Mobility in Aging and holds a Tier 1 Canada Research Chair in Geroscience. Lauren E. Griffith is supported by the McLaughlin Foundation Professorship in Population and Public Health. Anne Gilsing was supported by a CIHR Postdoctoral Fellowship and a Michael G DeGroote Fellowship Award from McMaster University.

Disclaimer The opinions expressed in this manuscript are the authors' own and do not reflect the views of the Canadian Longitudinal Study on Aging.

Competing interests None declared.

Patient consent for publication Not required.

Ethics approval This study was approved by the Hamilton Integrated Research Ethics Board (ID 09-213 and 10-423). The participant data were deidentified at the CLSA Data Curation Centre prior to their release to the study team. Participants gave informed consent to participate in the study before taking part.

Provenance and peer review Not commissioned; externally peer reviewed.

Data availability statement Data may be obtained from a third party and are not publicly available. Data are available from the Canadian Longitudinal Study on Aging (www.clsa-elcv.ca) for researchers who meet the criteria for access to deidentified CLSA data.

Supplemental material This content has been supplied by the author(s). It has not been vetted by BMJ Publishing Group Limited (BMJ) and may not have been peer-reviewed. Any opinions or recommendations discussed are solely those of the author(s) and are not endorsed by BMJ. BMJ disclaims all liability and responsibility arising from any reliance placed on the content. Where the content includes any translated material, BMJ does not warrant the accuracy and reliability of the translations (including but not limited to local regulations, clinical guidelines, terminology, drug names and drug dosages), and is not responsible for any error and/or omissions arising from translation and adaptation or otherwise.
Open access This is an open access article distributed in accordance with the Creative Commons Attribution Non Commercial (CC BY-NC 4.0) license, which permits others to distribute, remix, adapt, build upon this work non-commercially, and license their derivative works on different terms, provided the original work is properly cited, appropriate credit is given, any changes made indicated, and the use is non-commercial. See: http://creativecommons.org/licenses/by-nc/4.0/.

ORCID iDs

Divya Joshi http://orcid.org/0000-0003-3190-8866

Lauren E Griffith http://orcid.org/0000-0002-2794-9692

\section{REFERENCES}

1 Bath PA, Deeg D. Social engagement and health outcomes among older people: introduction to a special section. Eur J Ageing 2005;2:24-30.

2 Hsu HC. Does social participation by the elderly reduce mortality and cognitive impairment? Aging Ment Health 2007;11:699-707.

3 Holt-Lunstad J, Smith TB, Layton JB. Social relationships and mortality risk: a meta-analytic review. PLoS Med 2010;7:e1000316.

4 Maier H, Klumb PL. Social participation and survival at older ages: is the effect driven by activity content or context? Eur J Ageing 2005;2:31-9.

5 Turcotte P-L, Carrier A, Roy V, et al. Occupational therapists' contributions to fostering older adults' social participation: A scoping review. British Journal of Occupational Therapy 2018;81:427-49.

6 Holmes WR, Joseph J. Social participation and healthy ageing: a neglected, significant protective factor for chronic non communicable conditions. Global Health 2011;7:43.

7 Aida J, Kondo K, Hirai $\mathrm{H}$, et al. Assessing the association between all-cause mortality and multiple aspects of individual social capital among the older Japanese. BMC Public Health 2011;11:499.

8 World Health Organization. Decade of healthy aging: 2020-2030 2019:1-27

9 Avlund K, Due P, Holstein BE, et al. Changes in social relations in old age. are they influenced by functional ability? Aging Clin Exp Res 2002;14:56-64

10 Griffith L, Raina P, Wu H, et al. Population attributable risk for functional disability associated with chronic conditions in Canadian older adults. Age Ageing 2010;39:738-45.

11 Galenkamp H, Deeg DJH. Increasing social participation of older people: are there different barriers for those in poor health? introduction to the special section. Eur J Ageing 2016;13:87-90.

12 Tak E, Kuiper R, Chorus A, et al. Prevention of onset and progression of basic ADL disability by physical activity in community dwelling older adults: a meta-analysis. Ageing Res Rev 2013;12:329-38.

13 Stuck AE, Walthert JM, Nikolaus T, et al. Risk factors for functional status decline in community-living elderly people: a systematic literature review. Soc Sci Med 1999;48:445-69.

$14 \mathrm{Kim}$ J, Lee Y. Frequency of dairy consumption and functional disability in older persons. J Nutr Health Aging 2011;15:795-800.

15 McGrath R, Stastny S, Casperson S, et al. Daily protein intake and distribution of daily protein consumed decreases odds for functional disability in older Americans. J Aging Health 2020;32:1075-83.

16 Pahor M, Guralnik JM, Ambrosius WT, et al. Effect of structured physical activity on prevention of major mobility disability in older adults: the life study randomized clinical trial. JAMA 2014;311:2387-96

17 Liao W-C, Li C-R, Lin Y-C, et al. Healthy behaviors and onset of functional disability in older adults: results of a national longitudinal study. J Am Geriatr Soc 2011;59:200-6.

18 Karlamangla AS, Sarkisian CA, Kado DM, et al. Light to moderate alcohol consumption and disability: variable benefits by health status. Am J Epidemiol 2009;169:96-104.

19 Kikuchi H, Inoue S, Fukushima N, et al. Social participation among older adults not engaged in full- or part-time work is associated with more physical activity and less sedentary time. Geriatr Gerontol Int 2017;17:1921-7.

20 Samuel LJ, Dennison Himmelfarb CR, Szklo M, et al. Social engagement and chronic disease risk behaviors: the multi-ethnic study of atherosclerosis. Prev Med 2015;71:61-6.

21 Lindström M, Giordano GN. Changes in social capital and cigarette smoking behavior over time: a population-based panel study of temporal relationships. Nicotine Tob Res 2016;18:2106-14.

22 Van Holle V, McNaughton SA, Teychenne M, et al. Social and physical environmental correlates of adults' weekend sitting time and moderating effects of retirement status and physical health. Int $J$ Environ Res Public Health 2014;11:9790-810. 
23 Yun EH, Kang YH, Lim MK, et al. The role of social support and social networks in smoking behavior among middle and older aged people in rural areas of South Korea: a cross-sectional study. BMC Public Health 2010;10:78.

24 Chuang Y-C, Chuang K-Y. Gender differences in relationships between social capital and individual smoking and drinking behavior in Taiwan. Soc Sci Med 2008;67:1321-30.

25 Raina P, Wolfson C, Kirkland S, et al. Cohort profile: the Canadian longitudinal study on aging (CLSA). Int J Epidemiol 2019;48:1752-3.

26 Levasseur M, Gauvin L, Richard L, et al. Associations between perceived proximity to neighborhood resources, disability, and social participation among community-dwelling older adults: results from the VoisiNuAge study. Arch Phys Med Rehabil 2011;92:1979-86.

27 Levasseur M, Cohen AA, Dubois M-F, et al. Environmental factors associated with social participation of older adults living in metropolitan, urban, and rural areas: the nuage study. Am J Public Health 2015;105:1718-25.

28 Fillenbaum GG, Smyer MA. The development, validity, and reliability of the OARS multidimensional functional assessment questionnaire. $J$ Gerontol 1981;36:428-34.

29 Everage NJ, Linkletter CD, Gjelsvik A, et al. Implementation of permutation testing to determine clustering of social and behavioral risk factors for coronary heart disease, National health and nutrition examination survey 2001-2004. Ann Epidemiol 2013;23:381-7.

30 Keller HH, Goy R, Kane S-L. Validity and reliability of screen II (seniors in the community: risk evaluation for eating and nutrition, version II). Eur J Clin Nutr 2005;59:1149-57.

31 Washburn RA, McAuley E, Katula J, et al. The physical activity scale for the elderly (PASE): evidence for validity. J Clin Epidemiol 1999;52:643-51.

32 World Health Organization. Global recommendations on physical activity for health [Internet]. Geneva, Switzerland: World Health Organization, 2010.

33 Centers for Disease Control Prevention. The United States Department of Health and Human Services. In: Physical activity guidelines for Americans. 2nd ed. Washington, DC, 2008.
34 Canadian Centre on Substance Abuse and Addiction. Knowing your limits with alcohol: a practice guide to assessing your dirnking, 2019: 1-40.

35 Adler N, Stewart J. The MacArthur Scale of Subjective Social Status [Internet], 2007. Available: http://www.macses.ucsf.edu/Research/ Psychosocial/subjective.php

36 Sanchón-Macias MV, Prieto-Salceda D, Bover-Bover A, et al. Relationship between subjective social status and perceived health among Latin American immigrant women. Rev Lat Am Enfermagem 2013;21:1353-9.

37 White IR, Royston P, Wood AM. Multiple imputation using chained equations: issues and guidance for practice. Stat Med 2011;30:377-99.

38 Rimmer JH, Riley B, Wang E, et al. Accessibility of health clubs for people with mobility disabilities and visual impairments. Am J Public Health 2005;95:2022-8.

39 Rosso AL, Taylor JA, Tabb LP, et al. Mobility, disability, and social engagement in older adults. J Aging Health 2013;25:617-37.

40 Hästbacka E, Nygård M, Nyqvist F. Barriers and facilitators to societal participation of people with disabilities: a scoping review of studies concerning European countries. Alter 2016;10:201-20.

41 Gao M, Sa Z, Li Y, et al. Does social participation reduce the risk of functional disability among older adults in China? A survival analysis using the 2005-2011 waves of the CLHLS data. BMC Geriatr 2018;18:224.

42 Mendes de Leon CF, Glass TA, Berkman LF. Social engagement and disability in a community population of older adults: the new Haven EPESE. Am J Epidemiol 2003;157:633-42.

43 Berkman LF, Glass T, Brissette I, et al. From social integration to health: Durkheim in the new millennium. Soc Sci Med 2000;51:843-57.

44 Rapacciuolo A, Perrone Filardi P, Cuomo R, et al. The impact of social and cultural engagement and dieting on well-being and resilience in a group of residents in the metropolitan area of Naples. $J$ Aging Res 2016;2016 